\title{
Describing the use of discourse markers by ESL learners in writing
}

Nor Ashikin Ab Manan ${ }^{1, *}$, Nor Nadia Raslee ${ }^{2}$

${ }^{1}$ Academy of Language Studies, Universiti Teknologi MARA, 32610 Bandar Seri Iskandar, Perak, Malaysia

${ }^{2}$ Academy of Language Studies, Universiti Teknologi MARA, 35400 Tapah Road, Perak, Malaysia

\section{A RT I C LE IN F O}

Article history:

Received 7 November 2016

Received in revised form

16 January 2017

Accepted 20 January 2017

Keywords:

Discourse markers

Overused

Misused

Writing ability

\begin{abstract}
A B S T R A C T
This research paper describes the use of discourse markers (henceforth DMs) in paragraph writing by English as second language (ESL) learners who were enrolled in a writing class. 25 diploma level students from Landscape Architecture programme participated in the study. The main objective of the study was to investigate the use of DMs in paragraph writing by these learners. 50 paragraphs written by the participants were scrutinized and the DMs used in each paragraph were recorded. The DMs used by the participants were classified into four categories; a) Contrastive Markers (CDMs); b) Elaborative Markers (EDMs); c) Implicative Markers (IDMs) and d) Temporal Markers (TDMs). It was found that the participants use Elaborative Markers (73\%) the most followed by Temporal Markers (13\%), Contrastive Markers (8\%) and Implicative Markers (6\%). There is a weak linear relationship ( $r=0.007$ ) between the variety of DM used and the scores awarded to the paragraphs and a weak non-linear relationship ( $\mathrm{r}=-0.004$ ) between the total number of DMs used and the scores awarded to the paragraphs. It was concluded that the students had overused the high frequency EDMs such as 'and' and 'because' and had misused some DMs in their writing. The study concluded that EFL learners tend to use more limited and redundant sets of DMs in their writing due to their low English language proficiency.
\end{abstract}

(c) 2017 The Authors. Published by IASE. This is an open access article under the CC BY-NC-ND license (http://creativecommons.org/licenses/by-nc-nd/4.0/).

\section{Introduction}

Of the four language skills, learning to write is the most challenging for English as second language (ESL) learners. The ability to write well is essential for university students because their academic success depends on how well they are able to express themselves in writing. This is due to the fact that university students' academic success is assessed mainly through their written work such as assignments, reports, term papers and other written assessments.

\subsection{Background of the study}

English is taught as a subject in Malaysian schools both at the primary and the secondary levels and by the time the students enroll into tertiary level programmes they would have had at least eleven years of formal English language instruction.

\footnotetext{
* Corresponding Author.

Email Address: noras914@perak.uitm.edu.my (N. A. A. Manan) https://doi.org/10.21833/ijaas.2017.03.016

2313-626X/C 2017 The Authors. Published by IASE.

This is an open access article under the CC BY-NC-ND license

(http://creativecommons.org/licenses/by-nc-nd/4.0/)
}

However, for many of these undergraduates the length of exposure to English is not reflected in their proficiency level. The transition from school to university culture in itself is already very demanding for many of them. The difficulty faced by the students in coping with their content studies is further compounded by their lack of proficiency in English especially in writing.

According to Ting and Tee (2008) who conducted their study among Malaysian undergraduates, the subjects had poor academic writing skill especially in terms of the development of ideas in various stages. At the same time, language features such as modality, conditional clauses and connectors were not appropriately used.

\subsection{Problem statement}

One of the main concerns of ESL teachers is 'grammar'. Much of class time and energy are directed to the teaching of grammatical forms. However, other aspects of written discourse which are equally important but often overlooked are coherence and cohesion (Modhish, 2012). One way to achieve coherence in writing is through words and context (Kies, 2003). The use of DMs is one 
effective way to ensure coherence and cohesion. However, due to lack of understanding of the functions of DMs many ESL learners tend to overuse or underuse them in their writing (Yunus and Haris, 2014).

\subsection{The objectives of the study}

The main objective of this article is to describe the use of DMs in paragraph writing by 25 Malaysian ESL learners enrolled in a writing course. It aims to address the following research questions: a) what are the DMs used by the subjects in their paragraph writing? b) What categories of DMs are overused and misused by the subjects?

\section{Review of related literature}

Different linguists have different ways of defining discourse markers (DMs), depending on their research and subject areas. Among the terminologies used are sentence connectors (Halliday and Hasan, 1976), discourse connectives (Blakemore, 1992) or pragmatic markers (Fraser, 1999), cue phrases (Knott and Dale, 1994), discourse connectives (Redeker, 1990) and discourse signaling devices (Polanyi and Scha, 1983). Fraser (1999) stresses that DMs are conjunctions, adverbs and prepositional phrases that link two sentences or clauses together, while Redeker (1990) stated that DMs not only connect adjacent sentences but also join the current sentence or statement with its near context. Among the many definitions of DMs in the literature, it is felt that Swan (2005) definition is the best. According to Swan (2005), discourse markers are words and expressions that we use to portray the structure of our discourse. They serve the purpose of connecting what we are saying, what we have said and what will be said.

\subsection{DMs in oral communication}

Several studies have been conducted on the use of DMs in listening comprehension specifically in academic lectures (Benson, 1994; Flowerdew, 1994; Waggoner, 1984). The studies of DMs in academic lectures were mostly two-pronged. Firstly, it was studied from the perspectives of lecturing styles, whether reading or conversational style and secondly whether the lecture was delivered from native or non-native speakers. Another type of DM research was to study dialogic lecture styles in the higher institutions for instance, in group discussions, consultations or seminars (Chen, 2014). The monologic style lecture is the most commonly observed in higher institutions and it demands from listeners the ability to understand and deduce the semantics of what the speaker is delivering verbally in the monologues (Thompson, 1994). In such monologic lectures, when there is an absence of DMs, there exist difficulties for the listeners to recognize 'cues within lecture talk' (Chen, 2014).
ESL learners, depend greatly on the use of DMs in listening comprehension (Thompson, 2003). In order to understand lectures, ESL learners have to manage the auditory, cognitive and linguistic demands thus the use of DMs helps greatly to provide clues in construing the tasks in real time (Chen, 2014). According to Thompson (2003), when used in speeches, DMs help transform sentences and words into a mental map, which shows how each part interconnects.

Comparatively, there were studies conducted on dialogic lecture style. Lemke (1990) perceived dialogue as relevant to a discussion, for example in classroom seminars. Relevant findings of dialogic lecture style revealed that DMs are important because they fulfill textual and interpersonal purposes, which are very important for coherence and structure of the discourse (Castro, 2009).

\subsection{DMs in writing}

The process of writing can be difficult even for native speakers. If native speakers find it challenging, what more for nonnative language learners. The process of writing places a lot of demands on the writers. In order to write well, the writer needs to possess sufficient knowledge of vocabulary and grammar. The writer also needs to ensure coherence and cohesion of his written text. Texts which are coherent will ensure that even language beginners can navigate through the material. Cohesion is achieved through the use of proper and suitably joined phrases and sentences, which are elaborated into paragraphs. One key importance of achieving and fulfilling such demands in writing is through the successful application of discourse markers.

DMs are advantageous in which they allow speakers or writers to make their presence felt by pausing. DMs also provide guidance to the audience as to how the text is structured. Appropriately used DMs in writing helps provide arrangements particularly in introductions and conclusions to academic writings (Wei, 2013).

DMs allow readers and listeners to pause and process linguistic signals due to segmentations that they provide. Though DMs are optional, does not have grammatical effects and carry little weight semantically, if they are removed, it would make the interaction awkward, unnatural, impolite, unfriendly or dictatorial (Brinton, 1996). Fraser (1999) also remarked that without DMs, communication breakdown might happen. DMs play an important part in semantic cohesion (Halliday and Hasan, 1976) in which it helps construct function and meaning (Schiffrin, 1987). It was also found that ESL writers who used DMs aptly and effectively produced a better quality of writing (Jalilifar, 2008; Martinez, 2002).

The two-fold functions of DMs, which are the textual and the interpersonal function, are particularly significant in the process of teaching and learning. Wei (2013) perceived that in ESL, the use of 
DMs will lead to better communication, more structured writing, better interpretation of texts and speech and on the whole help improve learners' skills not only in speaking and writing but also listening and reading. In fact, the use of DMs is not only beneficial in the teaching and learning of English language but also other disciplines. Through the use of DMs, readers may achieve more efficient understanding of concepts, and the structure of technical writing can be greatly improved (Wei, 2013).

This article has adopted the semantic perspective by Fraser (2004) in classifying DMs. DMs are divided into four categories as follows.

a) Contrastive Markers (CDMs) such as alternatively, in spite of, conversely, but, although, in contrast, despite...

b)Elaborative Markers (EDMs) such as by the same token, in particular, above all, equally, also, for example, and...

c) Implicative Markers (IDMs) such as a conclusion, all things considered, so, as a consequence, after all, therefore, accordingly, hence, then...

d) Temporal Markers (TDM) such as eventually, as soon as, meantime, then, finally, before, meanwhile, first, after.

\subsection{DM use among ESL learners}

In research carried out on the use of contrastive markers (CDMs) among the Japanese and Koreans ESL learners in writing (Yin, 2005), it was found that the subjects used only CDMs they are familiar with. The CDM 'but' was most popularly used and it was only due to their habit of directly translating from their mother tongue into English. Yin (2005) attributed the limited and restricted use of CDMs to their fear or making mistakes.

Jalilifar (2008) and Rahimi (2011) studied the use of DMs among Iranian EFL learners in different writing genres. The former investigated the use of DMs in descriptive writing while the latter analyzed and compared the use of DMs in argumentative and expository writings. Both studies found that elaborative DMs are the most frequently used. In descriptive writing, inferential DMs were used more often than contrastive and causative DMs. However, for argumentative and expository writings, contrastive DMs were used more frequently than inferential markers.

One of the issues confronting ESL learners is they fail to use DMs effectively in their essays. This often results in poor structure and organization of ideas in their writing (Ayman and Khaled, 2013). Most often, audience become confused by what the author intended to deliver. This may be caused by the incorrect or improper use of DMs or simply, the absence of it. Lack of DMs creates holes in the structure and organization. Consequently, the readers would find it difficult to understand what the writer means and unable to predict the writer's intention.
Alghamdi (2014) analyzed DMs used by ESL learners in personal narrative and argumentative papers by native speakers (NSs) and non-native speakers (NNSs). In both types of composition, NS and NNS writers used elaborative, contrastive and reason markers at higher rates than any DMs in other categories, forming, as consequence, a hierarchy of use. Analysis of NNS writings showed an overuse of DMs at sentence-initial position and an unnecessary use of semantically similar DMs within the boundary of a single sentence. It also concluded that incorrect use and the frequency of DMs found in the writing were key indicators of the quality of ESL writings.

Mahmoud and Salim (2016) investigated the use of DMs in expository essays written by Jordanian EFL learners from different levels of English language proficiency found that the choice of DM used is affected by EFL learners' proficiency levels. Lower proficiency EFL learners tend to use more restricted and redundant sets of DMs. It was concluded that the use of discourse markers is affected by the proficiency levels of EFL learners.

\section{Methodology}

This study is conducted to investigate the use of DMs in paragraph writing by 25 ESL learners. It is descriptive in nature and the results of the findings will be reported as such.

\subsection{Participants}

The participants for this study were 25 second year Diploma in Landscape Architecture students enrolled in English as a second language (ESL) writing class. They were homogeneous in terms of age-group (19-21 years old), mother tongue (Malay) and educational background. They had attended proficiency English language course level 1 and 2 in their first and second semester respectively.

\subsection{Data collection procedure}

The participants in the study were instructed to write two paragraphs of 150 words each based on two different topic sentences. The first topic sentence was "Public speaking can develop students' self-confidence" and the second topic sentence was "One of the reasons why people move to big cities is to look for job opportunities".

The scripts were analytically scored by an independent scorer. The full marks allocated for both paragraphs were 10 which were then converted to $100 \%$. The division of marks was as follows: Content $=4$, Language $=4$ and Organization $=2$.

\section{Results and discussion}

Table 1 shows the summary of DMs used by the participants. 
Table 1: Summary of DMs used by the participants

\begin{tabular}{cc}
\hline Discourse Marker Categories & Discourse markers used by the learners \\
\hline Temporal Discourse Markers (TDM) & Firstly, secondly, thirdly, lastly, next, as \\
Implicative Discourse Markers (IDM) & Then, therefore, as a conclusion, thus \\
Elaborative Discourse Markers (EDM) & And, also, for example, besides, moreover, furthermore, such as, \\
Contrastive Discourse Markers (CDM) & because, in addition, aside from that \\
However, but, although, or, otherwise
\end{tabular}

The DMs used by the participants were classified into four categories as proposed by Fraser (2004):

a) Contrastive Markers (CDMs),

b) Elaborative Markers (EDMs),

c) Implicative Markers (IDMs) and

d) Temporal Markers (TDMs).

Based on Table 1, it can be seen that the participants had used in total only 24 different DMs which involved 6 TDMs, 4 IDMs, 10 EDMs and 4 CDMs.

Fig. 1 shows DMs used according to categories. It was found that the participants use Elaborative Markers (73\%), the most followed by Temporal Markers (13\%), Contrastive Markers (8\%) and Implicative Markers (6\%).

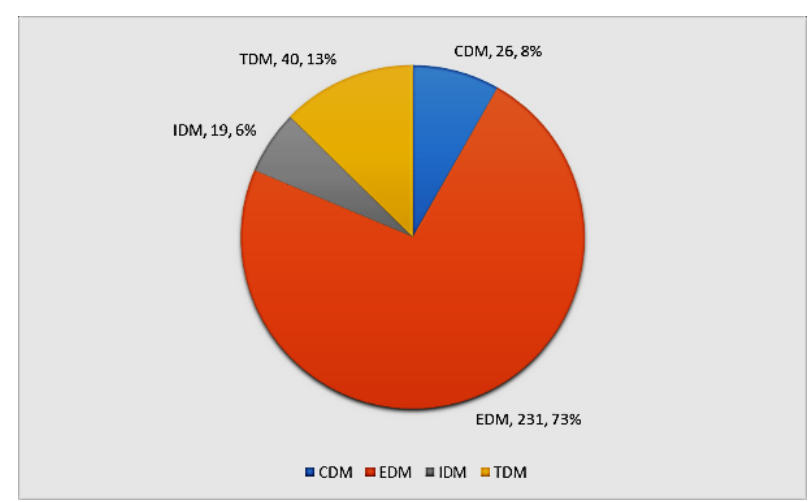

Fig. 1: DMs used according to categories

Meanwhile, Fig. 2 shows the summary of all DMs used by the participants. The findings are consistent with the findings of earlier research by Martinez (2004), Jalilifar (2008) and Rahimi (2011) who also found that ESL/EFL learners in their studies used a high number of elaborative DMs in their writings. They tend to use high frequency EDMs such as 'and', 'also', 'because' and 'for example'. There is a possibility that the limited use of other markers such as IDM and CDM is due to the fact that these learners lack proficiency in English. Thus, they tend to fall back on 'high frequency' markers to help them in their writing.

Fig. 3 shows the use of DMs by each student. The students' identification (ID) and their respective scores are displayed vertically while the frequency of DM used according to categories is shown horizontally. For example, participant number one (P01) scored 30 over 100 and used 0 CDM, 12 EDM, 1 IDM and 1 TDM. Based on Fig. 3, it can be seen that the highest score is 65 (P02) and the lowest is 25 (P11). The range is 40. The mode is 50 and the median is 40 . The average score is 40.08 while the standard deviation is 11.43 . It can be concluded that the majority of the students in the study are weak in writing. Only 10 out of 25 students passed the test with the score of above 50 . The highest score is 65 which is equivalent to the letter grade " $\mathrm{B}$ ".

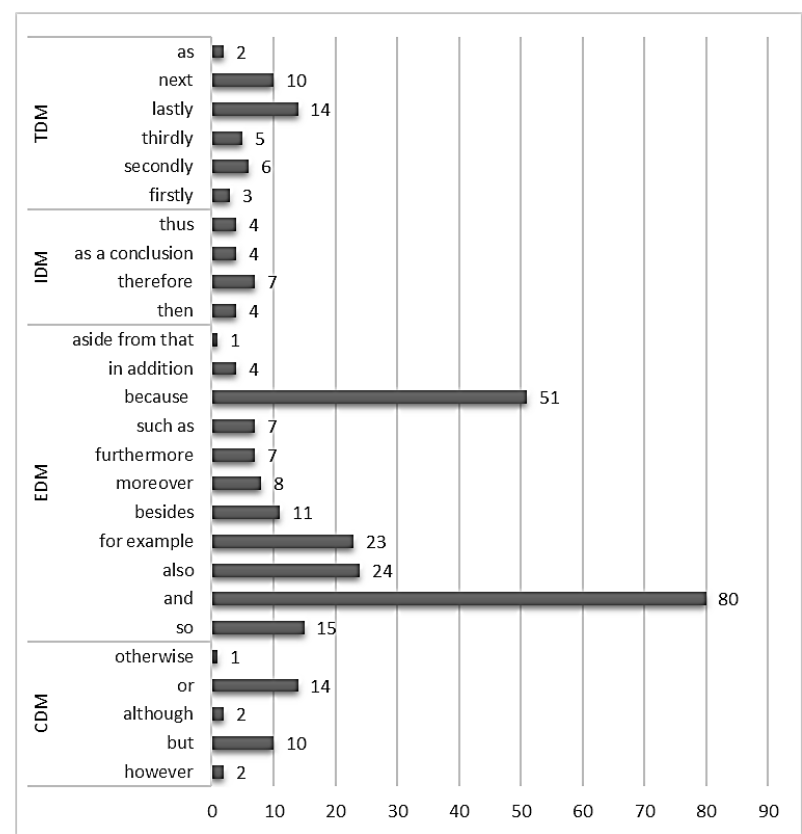

Fig. 2: The frequency count of DMs used

In order to determine whether there is a relationship between the variety of DM used and the scores, and the relationship between the total number of DM used and the scores, Pearson's correlation statistical analysis was conducted. It was found that the correlation is not significant and there is only a weak linear relationship $(r=0.007)$ between the variety of DM used and the scores awarded to the paragraphs and a weak non-linear relationship ( $\mathrm{r}=-0.004$ ) between the total number of DMs used and the scores awarded to the paragraphs. It can be concluded that a high frequency of DMs use is not directly related to their paragraph writing scores. Based on Fig. 3, student P16 used a total of 23 DMs in his paragraph writing but scores only 38 marks while student P06 who scores 60 marks had used only 9 DMs. These are inconsistent with Martinez's (2002, 2004) conclusions that the frequency of DMs used is an indicator of the quality of the composition and the score awarded to it.

The test scripts were analyzed and it was found that many of the participants had produced poor quality sentences. Many of the participants wrote simple sentences that were choppy and immature while others attempted to produce long compound sentences but were grammatically incorrect.

With the exception of two participants (P02 and P06), other participants in the study can be 
categorized as 'average' and 'limited' writers based on their paragraph writing test scores. Some of the participants had misused the DMs in their writing. Table 2 shows excerpts of test scripts where the students had misused the DMs in their writing.

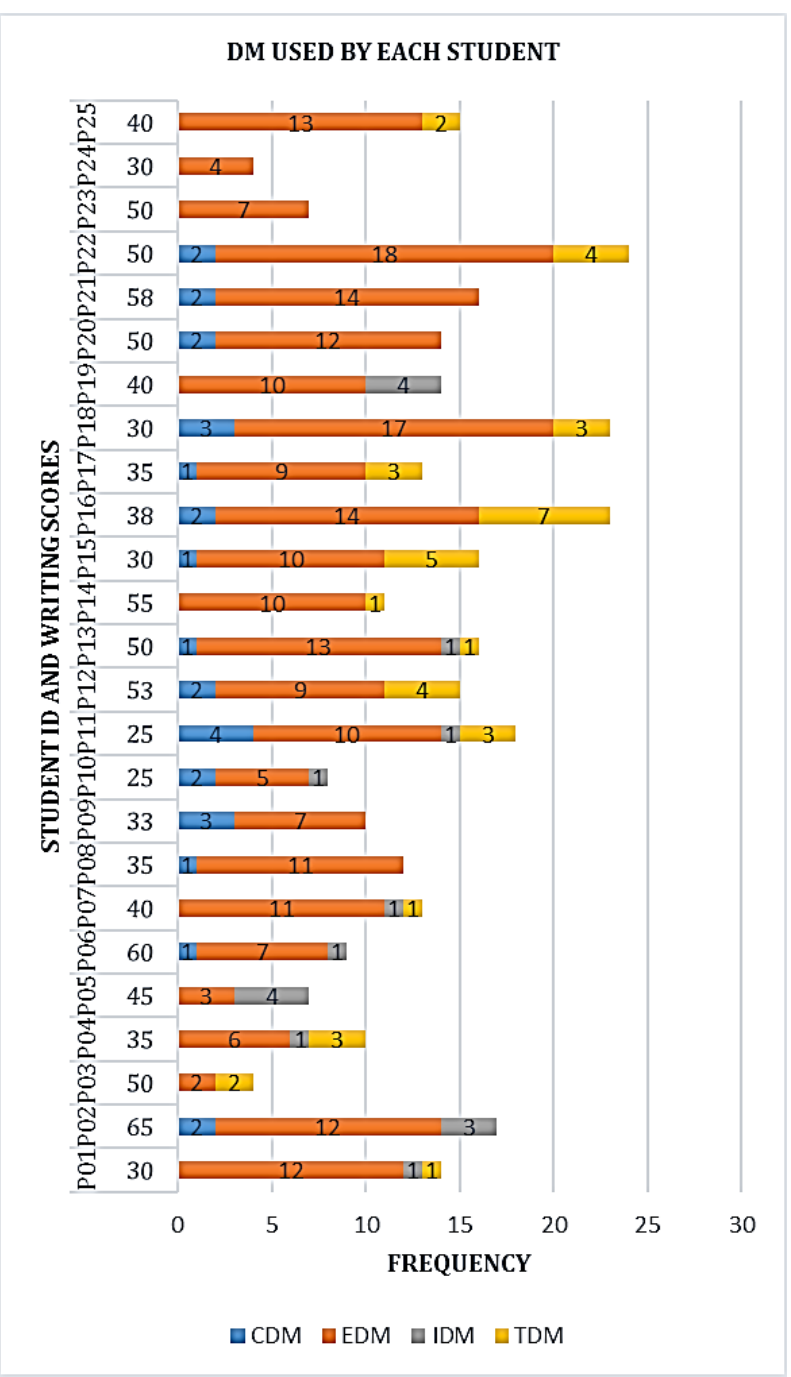

Fig. 3: DM used by each student

Table 2: Sample of misuse of DMs

\begin{tabular}{cl}
\hline Participants & \multicolumn{1}{c}{ Excerpts } \\
\hline \multirow{2}{*}{ P01 } & $\begin{array}{l}\text { We can find job in big cities for all education } \\
\text { levels. Besides, people can go places easily or } \\
\text { shop anywhere they like. However, people } \\
\text { move to big cities because the line of } \\
\text { communication is better... }\end{array}$ \\
& $\begin{array}{l}\text { Public speaking can develop students' self- } \\
\text { confidence. However, if they join competition } \\
\text {...they will decrease their nervousness. }\end{array}$ \\
\hline
\end{tabular}

In both excerpts the participants had misused the CDM 'however'. Instead of CDM, they should have used EDMs to make their sentences correct.

Another common problem among the participants is over usage of DMs. Table 3 shows the excerpts of test scripts where the students had overused the DMs in their writing. In both excerpts the participants had overused the DMs to make up for their limited vocabulary. They had overused high frequency DMs such as 'and' and 'because' in their sentences due to the fact that they have not acquired the skill of writing compound sentences yet. As a result, their sentences are 'unnatural' and 'awkward'.

Table 3: Sample of overuse of DMs

\begin{tabular}{cl}
\hline Participants & \multicolumn{1}{c}{ Excerpts } \\
\hline \multirow{4}{*}{ P07 } & $\begin{array}{l}\text { Many people take their chances to look for } \\
\text { jobs in big cities because they want to find } \\
\text { suitable place for their family and feed them } \\
\text { and to send their children to school so that } \\
\text { they will feel comfortable. } \\
\text { Public speaking can increase students' } \\
\text { confidence because when they stand on stage } \\
\text { they will be brave and if they continue to join } \\
\text { competition and so on they will decrease their } \\
\text { panic and increase their self-confidence. }\end{array}$ \\
\hline
\end{tabular}

\section{Conclusion}

It can be concluded that the majority of the participants in the study are 'limited' ESL writers. They have yet to develop their writing skills to meet the challenges of tertiary level studies. The use of DMs in their paragraph writing did not contribute to better coherence and cohesion in many instances because they had either misused or overused them. The findings of the study correspond with earlier study conducted by Mahmoud and Salim (2016). Lower proficiency EFL learners tend to use more limited and redundant sets of DMs and the use of DMs is affected by the proficiency levels of the learners. It is recommended that the students' ability to use discourse markers should be developed to improve their writing performance.

\section{References}

Alghamdi EA (2014). Discourse markers in ESL personal narrative and argumentative papers: A qualitative and quantitative analysis. International Journal of Humanities and Social Science, 4(4): 294-305.

Ayman SDA and Khaled A (2013). The use of discourse markers in paragraph writings: The case of preparatory year program students in Qassim University. English Language Teaching, 6(9): 217-227.

Benson MJ (1994). Lecture listening in an ethnographic perspective. In: John F (Eds.), Academic Listening: Research Perspectives: 181-198. Cambridge University Press, Cambridge, UK.

Blakemore D (1992). Understanding utterances: An introduction to pragmatics. Blackwell, Oxford, UK.

Brinton L (1996). Pragmatic markers in English: Grammaticalization and discourse functions. Walter de Gruyter, Berlin, Germany.

Castro CM (2009). The use and functions of discourse markers in EFL classroom interaction. Profile Issues in Teachers Professional Development, 11: 57-78.

Chen S (2014). A review of the role of discourse markers in ESL/EFL listening comprehension. Contemporary English Teaching and Learning in Non-English-Speaking Countries, 3(5): 1-27.

Flowerdew J (1994). Research of relevance to second language lecture comprehension: An overview. In: John F (Eds.), Academic Listening: Research Perspectives: 7-29. Cambridge University Press, Cambridge, UK.

Fraser B (1999). What are discourse markers?. Journal of Pragmatics, 31(7): 931-952. 
Fraser B (2004). An account of discourse markers. In: Garcés $P$, Gómez R, Fernández L, and Padilla M (Eds.), Current trends in Intercultural, Cognitive and Social Pragmatics: 13-34. Universidad de Sevilla, Sevilla, Spain.

Halliday MAK and Hasan R (1976). Cohesion in English. Longman, London, UK.

Jalilifar A (2008). Discourse markers in composition writings: The case of Iranian learners of English as a foreign language. English Language Teaching, 1(2): 114-122.

Kies D (2003). Coherence in writing. Available online at: http://papyr.com/hypertextbooks/engl101/coherent.htm.

Knott A and Dale R (1994). Using linguistic phenomena to motivate a set of coherence relations. Discourse Processes, 18(1): 35-62.

Lemke JL (1990). Talking science: Language, learning, and values. Ablex Publishing Corporation, New Jersey, USA.

Mahmoud AEA and Salim MR (2016). The use of discourse markers in written discourse by students of English at the University of Jordan. International Journal of Humanities and Social Science, 6(3): 23-35.

Martinez ACL (2002). The use of discourse markers in E.F.L. learners' writing. Revista Alicantina de Estudios Ingleses, 15: $123-132$.

Martinez ACL (2004). Discourse markers in the expository writing of Spanish university students. IBÉRICA: Revista de la Asociación Europea de Lenguas para Fines Específicos, 8: 6380.

Modhish A (2012). Use of discourse markers in the composition writings of Arab EFL learners. English Language Teaching, 5(5): 56-61.

Polanyi L and Scha R (1983). The syntax of discourse. TextInterdisciplinary Journal for the Study of Discourse, 3(3): 261270.
Rahimi M (2011). Discourse markers in argumentative and expository writing of Iranian EFL learners. World Journal of English Language, 1(2): 68-78.

Redeker G (1990). Ideational and pragmatic markers of discourse structure. Journal of Pragmatics, 14(3): 367-381.

Schiffrin D (1987). Discourse markers. Cambridge University Press, Cambridge, UK.

Swan M (2005). Practical English usage. Oxford University Press, Oxford, UK.

Thompson S (1994). Aspects of cohesion in monologue. Applied Linguistics, 15(1): 58-75.

Thompson S (2003). Text structuring metadiscourse, intonation and the signalling of organization in academic lectures. Journal of English for Academic Purposes 2(1): 5-20.

Ting SH and Tee PF (2008). TESL undergraduates' ability to handle academic text-type at University Malaysia Sarawak. Asiatic, 2(2): 86-100.

Waggoner M (1984). The new technologies versus the lecture tradition in higher education: Is change possible?. Educational Technologies, 24(3): 7-12.

Wei S (2013). The importance of discourse markers in English learning and teaching. Theory and Practice in Language Studies, 3(11): 2136-2140.

Yin W (2005). Narrow-sensed and broad-sensed grammaticalization. Journal of Sichuan International Studies University, 5: $15 . \quad$ Available online at: http://en.cnki.com.cn/Article_en/CJFDTOTAL-SCWY2005 05015.htm

Yunus M and Haris SNF (2014). The use of discourse markers among form four SLL students in essay writing. International Education Studies, 7(2): 54-63. 